\title{
Vila Real ou a micronação performática
}

\section{Antonia Cristina de Alencar Pires}

Doutora em Literatura Comparada pela Faculdade de Letras da UFMG; Mestre em Literatura Brasileira pela FALE/UFMG; Bacharel em Biblioteconomia pela Escola de Ciência da Informação da UFMG.

\section{Resumo}

Este artigo é uma leitura do romance Vila Real, de João Ubaldo Ribeiro analisando-o como uma narrativa "performática" (conceito criado pelo teórico Homi K. Bhabha). A partir de tal perspectiva, são observadas questões relacionadas à identidade cultural e ao sistema de identificação coletiva de um grupo de camponeses expropriados que busca estabelecer-se em algum lugar e que, desse modo configura-se como uma micronação.

Palavras-chave: Narrativa, Identidade Cultural, Micronação.

\section{Resumen}

Este artículo es una lectura de la novela de Vila Real de João Ubaldo Ribeiro y analiza la obra como una narración "performativo" (concepto creado por Homi K. Bhabha teórico). Desde esta perspectiva, son temas observados relacionados con la identidad cultural y al sistema identificación colectiva de un grupo de campesinos desposeídos que buscan establecerse en algún lugar y por lo tanto aparece como una nación micro.

Palabras clave: Narrativa, Identidad Cultural, Micro-Nación.

\section{Abstract}

This article is a reading of the novel Vila Real de João Ubaldo Ribeiro analyzing it as a narrative "performative" ( concept created by Homi K. Bhabha theoretical) . From this perspective, are observed issues related to cultural identity and to the system collective identification of a group of dispossessed peasants seeking to settle somewhere and thus appears as a micro nation

Key words: Narrative, Cultural Identity, Micro-Nation

Na contracapa da primeira edição de Vila Real (1979), seu terceiro romance, o escritor João Ubaldo Ribeiro faz a seguinte declaração: "Procuro basicamente fazer uma literatura comprometida com a afirmação da identidade brasileira". Esta afirmativa de Ribeiro ratifica, de fato, não apenas o texto mencionado, mas o conjunto de sua obra. 


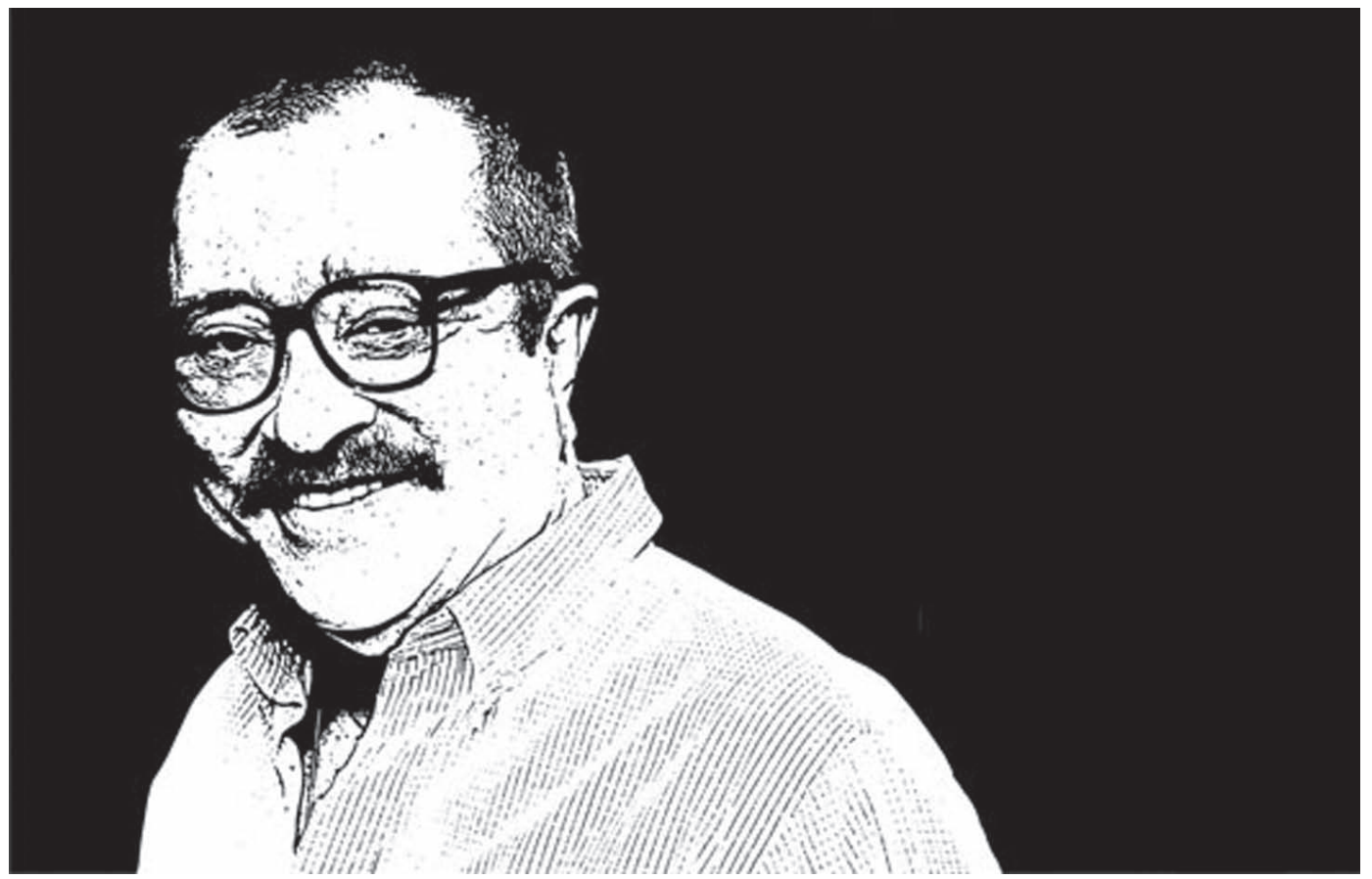

João Ubaldo Ribeiro (1941-2014).

Não seria demasiado afirmar que desde seu primeiro romance, Setembro não tem sentido (1967), esta preocupação já é acenada pelo escritor. Ao assinalar como compromisso básico de sua produção ficcional a questão da identidade, o escritor passa, portanto, a dialogar com a cultura e a História brasileiras, como fizeram alguns de seus precursores (entre estes, no meu entender, Lima Barreto, Oswald e Mário de Andrade).

Em Vila Real a preocupação com a questão da identidade é expressa através de um grupo de camponeses que luta para obter e preservar seu espaço. No espaço buscado, os camponeses desejam desenvolver sua cultura e tecer sua própria História ou, como nas palavras de Argemiro (um dos líderes do grupo), ser "generais da própria herança (RIBEIRO, 1979, p. 98). A permanência em um local significa a possibilidade de passarem, enfim, à condição de sujeitos. Lavrar, cultivar a terra, fixar-se a um território são metáforas da construção identitária. Inclusive por que a terra é elemento de reconhecimento para o grupo de camponeses. Todavia, a relação terra - território - identidade é barrada pela errância que lhes é imposta. Empurrado constantemente para o deslocamento, para a itinerância, esta passa a ser a condição de existência do grupo no mundo. Viver é deslocar-se. Deslocar-se é não viver.

Nas lembranças de Argemiro, visitadas pelo narrador, isto aparece muito claramente: "foram expulsos de Jurupema e vagaram como ciganos pelos ermos." Até que encontraram terra boa para roçar e assentar casas. Argemiro lembrou o tempo que as primeiras colheitas começaram e o movimento da feira em Vila Real (RIBEIRO, 1979, p. 15).

Ou ainda: já não se consentia que vivessem. Primeiro moraram na parte melhor da Jurupema, que não se chamava Aratanha. Corridos foram morar em Vila Real. De lá buscaram Aratanha, quando A Caravana Misteriosa fez com que eles saíssem de onde tinham plantado roças e pensavam sossegar (Idem, pp. 24-25).

Itinerância e lembrança traduzem-se em dois paradigmas emblemáticos, os quais são responsáveis no texto em questão pela articulação entre mito e História. O míti- 
co é representado pela ligação do homem com a terra e o histórico é esboçado nas desigualdades sociais, na intolerância com as minorias despossuídas. Lembre-se que o grupo nômade de Vila Real ora é perseguido pelos "Homens de Genebaldo", ora pela "Caravana Misteriosa". A articulação mito/História possibilita, ainda, o surgimento do sentido do texto e pode ser lida também como uma relação entre o mágico e o trágico. O mágico é representado nas visões do sobrenatural que a terra suscita e que perpassam todo o romance, configurando-se como o imaginário do grupo, sua fonte de explicação e compreensão do mundo. Ao passo que a guerra declarada ao grupo e a miséria material vivida por Argemiro e seu povo enfatizam a tragédia histórico-social em que estão imersos os despossuídos. Uma tragédia sublinhada pela morte e pela loucura, "únicas portas pelas quais é possível fugir do mundo", como disse Argemiro aos seus companheiros (Idem, p. 61).

A itinerância e a lembrança funcionam ainda como índices das instâncias de espaço e de tempo na narrativa ubaldiana. Estas instâncias são imprecisas e fragmentadas. A primeira instância (o espaço), de acordo com o exposto anteriormente, estende-se por vários locais (Jurupema, Vila Real e Aratanha), enquanto o tempo transcorre ora no presente da narrativa, ora no passado (nas lembranças de Argemiro e de outras personagens), mediado por um narrador em terceira pessoa. A imprecisão e a fragmentariedade espaço-temporal em que vivem as personagens, como se vê no texto, incide sobre a identidade subjetiva dos membros do grupo. Sempre em trânsito, as personagens de Vila Real são "estrangeiros em sua própria pátria", tanto quanto os imigrantes, os diaspóricos e os refugiados de guerra que experimentam o sentimento de viver a margem da Nação, como mostram os estudos de Homi K. Bhabha. Entretanto, o fato de estarem juntos cria traços de identificação entre os indivíduos. O compartilhamento do mesmo espaço (ainda que reduzido) durante algum tempo, permite essa possibilidade. É exatamente através destes traços identitários que se formam grupos como o representado em Vila Real. Tais grupos passam a ser considerados como micronações.

Mesmo que o conceito de Nação inclua o fator território, como nos explicam os estudos de Eric Hobsbawm sobre a formação dos Estados-nação (HOBSBAWM, 1988), e que o grupo liderado por Argemiro seja sempre obrigado a sair da área ocupada, ainda assim o conceito de micronação é aqui cabível. No caso do grupo focalizado, trata-se de uma pequena nação cujo território não é fixo. Poder-se-ia dizer que seu território é móvel, flutuante e que as fronteiras que o balizam não são de ordem geográfica, mas de ordem ideológica, dada à segregação imposta ao grupo. Cabe acrescentar que as micronações, apesar de serem um fato concreto, são veladas pelas instâncias de poder da macronação. Isto quando não são dissolvidas por meios violentos. Assim não é difícil entender por que o grupo de Vila Real é perseguido pelos "homens de Genebaldo" e pela "Caravana Misteriosa".

Ainda pensando em relação à ideia de Nação, sabemos através dos estudos de Homi K. Bhabha que tal ideia está calcada na homogeneidade, na aglutinação, no discurso da convergência. Segundo Bhabha, a melhor imagem da Nação é aquela que a associa a um bloco monolítico, sob um foco de luz, que permanece inteiro através dos tempos (BHABHA, 1994). Sendo assim, imagens relativas à corrosão, a dilacerações, a rachaduras, estão excluídas da imagem da nação. Entretanto, observado fora do foco de luz, o bloco-nação apresenta rachaduras. Estas vão de encontro ao discurso da convergência, revelando que o caráter nacional é divergente, marcado por 
interesses conflitantes. A dispersão dos indivíduos e dos grupos, por exemplo, é um fator responsável pelas cisões da Nação. Convém, portanto, lembrar que as narrativas ficcionais flagram tais cisões ao (re) apresentarem imagens opostas às imagens "pedagógicas", termo utilizado por Bhabha para se referir às imagens disseminadas pelo discurso nacional. As narrativas que expõem as fraturas da Nação são denominadas narrativas "performáticas" pelo mesmo teórico (Idem).

As narrativas de João Ubaldo Ribeiro se notabilizam por presentificar imagens da dispersão, da dilaceração, conforme pode se ver em outros textos, além de Vila Real. Convém também enfatizar que dispersão e dilaceração aparecem constantemente associadas nos textos ubaldianos, conforme procurei mostrar em minha tese de Doutorado (PIRES, 2000), e no artigo Laços desatados: o esfacelamento das referências em tempos de guerra flagrado em imagens ficcionais e fotográficas. Outra imagem utilizada por João Ubaldo Ribeiro é a da mutilação dos corpos como metáfora da exclusão das minorias. A decapitação de um padre em Vila Real emblematiza estas considerações. Leia-se:

“(...) temos só mais por nós as rezas. De padre Benedito eles cortaram a cabeça.

- Eu sei - respondeu Santo. - Eles cortaram a cabeça dele e enfiaram numa estaca para que o povo visse e amolecesse" (RIBEIRO, 1979, p. 60).

Em outros momentos, a dispersão ocorre pela via da mutilação simbólica. Neste caso, o texto ubaldiano volta-se para o questionamento da desapropriação do saber das comunidades minoritárias. Nessas comunidades o saber, o conhecimento é transmitido de modo informal de um indivíduo a outro. Sua preservação e transferência se fazem através da malha da memória comum a todos, ou seja, por meio da memória coletiva. Quando é diluído o saber informal (um dos elementos do sistema de identificação do grupo), o dissolvimento da comunidade é iminente. Através da fala de Argemiro, tal constatação é ratificada:

"Meninos, meninas, carreguem, guardem o que aprenderam e não deixem que lhes tirem nada dessa casa [...] o que se esquece se esturrica como os arbustos fracos na seca. [...] Existe muita coisa a ser aprendida, vamos escutar (Idem, p. 71).

Argemiro pede aos mais jovens que nada esqueçam. Manter a memória viva é também uma condição para sobrevivência. Resistir ao esquecimento é resistir às instâncias de poder que os perseguem, ou como explica Michael Pollak, alguns grupos ou povos são obrigados a esquecer determinadas circunstâncias que os cercam para que a ordem estabelecida não seja abalada (POLLOCK, 1989, pp. 3-15). Outro aspecto importante da fala da personagem, que é uma questão recorrente nos textos de João Ubaldo Ribeiro, é a discussão sobre o poder da palavra.

Em Vila Real, João Ubaldo Ribeiro problematiza a bidimencionalidade da palavra (sua forma oral e escrita) e o par verdadeiro/falso sobre o qual se assenta seu poder. A dupla dimensão da palavra saliente-se, torna visível a cisão natural dentro da mesma língua. A língua, um dos elementos do sistema de identificações coletivas, é concebida pelo discurso pedagógico da Nação como algo homogêneo e compartilhado por todos da mesma forma. Concepção essa que é desmentida pelo texto ubaldiano. Em relação à primeira problematização, Vila Real tematiza a armadilha 
e as trapaças provocadas pela dimensão escrita da palavra. $\mathrm{O}$ texto procura mostrar que ao engendrar trapaças, a escrita recria a realidade e reivindica para si o estatuto da verdade. Os jornais e os chamados "documentos oficiais" dão carnadura a estas considerações. Recorrendo ao próprio texto, destaco a fala da personagem Santo:

"[...] os juizes trabalham com papeis que aqui ninguém tem. Cada juiz faz sua edificação com uma porção de papeis e lá obrigam você a ter mais papeis. [...] E também existem os jornais, que são grandes folhas de mais papel, esse é comprado e vendido na rua e neles escrevem todas as historias que querem, [...]" (RIBEIRO, 1979, p. 71).

Para analisar em termos teóricos a problematização ensejada pela ficção, busco nos estudos de Levi Strauss reflexões que as corroboram. Conforme o mencionado antropólogo, a manipulação da palavra escrita é imprescindível para estabelecer a dominação e formar as hierarquias sociais. Levi Strauss mostra que não é sem razão, portanto, que os grupos que detém a escrita desenvolvem mecanismos para dificultar ou vedar o seu acesso por outros grupos. Desse modo, os indivíduos ficam incapacitados de decidir e de inferir na realidade e alterá-la (LEVI-STRAUSS, 1976). Os estudos de Levi Strauss citados referem-se à questão da colonização do mundo americano, entretanto, são válidos para pensarmos a situação do grupo de camponeses de Vila Real.É nítido no texto que o grupo não sabe ler nem escrever. Desse modo, acobertadas pelo caráter de legitimidade que a letra confere à palavra, as autoridades deliberam sobre a propriedade da terra. $\mathrm{O}$ excerto a seguir patenteia estas considerações. Em um encontro com um representante da lei, Argemiro sente a pressão exercida pelos papeis escritos, pelos documentos:

"Achou que se tratava de um confronto desleal, já que ele próprio tinha de improvisar depois de muitos sacrifícios, enquanto que o homem apenas lia no papel aquilo que pretendia dizer. $E$ também sentiu acanhamento em procurar falar mais, pois se bem que o homem fosse estrangeiro e sua lingua diversa, tinha vergonha de não saber a lingua dele e achava que ele podia corrigi-lo e, de qualquer forma, sempre havia de ter mais conhecimento" (RIBEIRO, 1979, pp. 35-36).

Nota-se, ademais, que não é apenas o registro escrito que intimida Argemiro. Há também uma "diversidade" de línguas. Falas diferentes em confronto. O falante letrado é tido como "estrangeiro" pelo homem não alfabetizado. A tensão flagrada pelo texto ubaldiano evidencia que a língua - considerada como fator de coesão e irmanamento de um povo - apresenta divergências internas. Essas divergências demonstram a heterogeneidade que marcam o território nacional. Verifica-se, assim, a existência de uma outra língua dentro da língua. Problema que o monolinguismo oficial não resolve, como indica Homi K Bhabha. Essa espécie de ambivalência "assombra" o conceito de nação, assusta a narrativa "pedagógica" e traz à tona a perplexidade das narrativas "performáticas". Segundo as proposições de Bhabha, a nação deve ser pensada enquanto narrativa, enquanto uma representação da vida social. Desse modo, a narrativa pedagógica corresponde ao patamar teórico, ideal, pautado pelas certezas e por uma verdade ideológica. Em síntese, é o olhar oficial a respeito da Nação. A narrativa performática é a narrativa que efetivamente vivencia os paradoxos da nação (BHABHA, 1994). As ambiguidades instaladas pela língua (oral/escrita, formal/ informal), vivenciadas profundamente pelas personagens de Vila Real, ensejam, como 


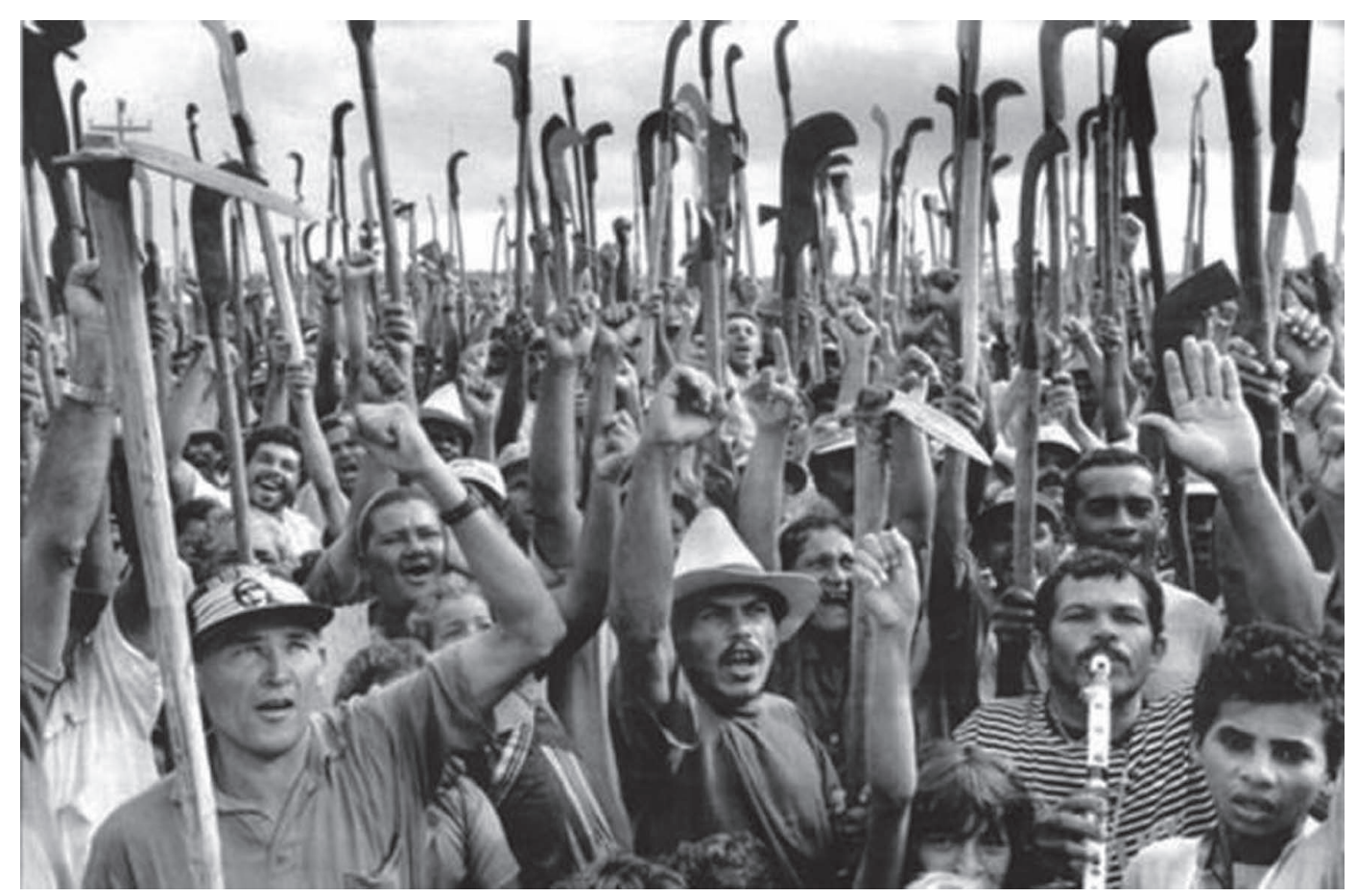

Manifestações dos trabalhadores rurais sem-terra, Sebastião Salgado.

se disse a princípio, o questionamento sobre o valor da verdade. A palavra seria sempre porta-voz da verdade? Ou a palavra é veneno que cura e também mata? Inserida nesse viés, a palavra é instrumento do conhecimento. Assim, o texto procura mostrar que nenhuma forma de conhecimento transmitida através da palavra é absolutamente verdadeira. Ou de outro modo: qualquer forma de conhecimento é liminar, portanto, não pode ser tomada como uma verdade absoluta. $\mathrm{O}$ diálogo entre um padre e um médico à página 85 de Vila Real leva-nos a tal entendimento.

Enquanto veneno, as mentiras que a palavra pode destilar são substâncias mortais. Ao passo que transmissora do saber lúdico/telúrico, enquanto disseminadora do conhecimento mítico mágico, a palavra é veneno curativo. É o substrato fundamental para a sobrevivência do grupo itinerante do texto ubaldiano. Fundamentados no conhecimento informal do mundo, os membros do grupo aglutinaram-se. $\mathrm{O}$ modo como compartilham, trabalham e se relacionam em seu locus vai, aos poucos, dando consistência e sabor ao caldo cultural que passam a representar, mesmo em seu contexto desterritorializado. O conjunto cultural corporificado na coletividade itinerante de Vila Real, pensado em conformidade com a teoria bhabhiana, deixa claro que a cultura nacional se articula a partir de muitos e diferentes traços e que esses são uma somatória de várias temporalidades, isto é, cada segmento cultural incorpora resíduos de muitas épocas ao mesmo tempo (BHABHA, 1979).

Aliás, as marcas temporais são bastante salientes em culturas que se utilizam do registro oral. Melhor dito: nesses tipos de culturas, o saber do presente mescla-se com o saber do passado. Isto se expressa em grande medida quando a figura dos velhos é de acentuado relevo nas comunidades como a do texto ubaldiano. Pensados como expressões da narrativa performática, pode se dizer que os muitos seguimentos culturais atuam polissemicamente na narrativa-Nação. Ainda de acordo com os conceitos de Bhabha, a cultura da comunidade de Vila Real é uma cultura performática. Uma 
corroboração de que o Outro não vive apenas do "lado de fora" da Nação; de que as margens do território nacional não estão do lado de lá de suas fronteiras, mas no seu próprio cerne (Idem).

A impossível unidade do caráter nacional sublinhada pela otredad, termo cunhado por Octavio Paz para se referir à condição do sujeito ibero-americano, é o que o texto ubaldiano reafirma ao longo de sua enunciação. João Ubaldo Ribeiro propõe ao leitor que observe a nação de outro ponto de vista, que se afaste do centro e percorra suas margens. Não é sem razão, pois, a presença do rio Japiau na narrativa. Além de ser metáfora do deslizamento (da palavra que escorre e da errância do grupo de Argemiro), o rio salienta a fluidez dos conceitos e dos objetos que se querem sólidos. Há que se lembrar, ainda que seu leito é sempre uma fenda a dividir a superfície de um terreno e que suas curvas são índices de descontinuidade.

A descontinuidade opõe-se, no caso, à noção de perenidade que circunda a ideia de Nação como um bloco monolítico. O descontínuo que o rio metaforiza, alcança desdobramento na referência inerente às sombras. Como disse anteriormente neste estudo, a imagem ideal da nação rejeita a sombra. Entretanto ela é inevitável, uma vez que todo objeto sob um foco de luz cria ao redor de si regiões de penumbra.

É para as zonas sombreadas que também certos eventos costumam ser empurrados. Isto ocorre, frequentemente, na narrativa historiográfica (uma das formas de narrativa pedagógica da Nação). Empurra-se para a sombra, sobretudo, aquilo que contraria o ideal linear e homogêneo da História. Empurram-se também os embates entre o pedagógico nacional e o performático das micronações que hibridizam as culturas modernas coloniais e pós-coloniais.

Em relação ao primeiro aspecto, explica-se que dentro de tal concepção de história (advinda do pensamento positivista do século XIX), os eventos históricos se efetuam sempre como continuidade, numa relação imediata e direta de causa e efeito, sugerindo, assim, uma horizontalidade temporal. Esta projeção em torno do tempo funciona como mecanismo de controle dos dominantes sobre a historicidade, como propôs Walter Benjamim. Desse modo, segundo o filósofo, torna-se possível disseminar a ideia de que se conhece e se sabe totalmente como foi o passado e assegura-se a perspectiva de um futuro calcado na ideologia do progresso (BENJAMIM, 1985). Cabe acrescentar que grupos como o de Argemiro, que não detém a escrita nem o conhecimento dito "científico" do mundo, vão de encontro à ideologia do progresso, pois representam o "velho", em oposição ao "novo" que o progresso julga representar.

Com relação ao segundo aspecto, o confronto entre o pedagógico e o performático, é Bhabha quem nos explica que isso ocorre por que, em termos de historicidade, para o pedagógico, os povos são apenas objetos históricos. Para o performático, os povos são sujeitos de um processo de significação histórica.

Assim, como se disse, o grupo liderado por Argemiro é empurrado cada vez mais para fora do que pertence à historicidade dominante. $\mathrm{O}$ modelo de organização de sua comunidade não condiz com os paradigmas de tempo e espaço ensejados pelo processo histórico dominante e nem com a concepção de progresso advinda do positivismo.

A comunidade de Vila Real, em sua aparente insubordinação, constrói sua significação histórica e esta pertence ao âmbito da dissonância. Vivendo de modo arcaico (do ponto de vista dominante), entre lendas e mitos, utilizando-se do saber veiculado pela memória coletiva, pelas narrativas orais, o grupo de Argemiro é um enigma que assusta a "normalidade", a concepção óbvia de Nação e de identidade fundamentadas 
no unitário. $\mathrm{O}$ rio com suas curvas, com seus mistérios, suas figuras distorcidas, suas assombrações; a terra, berço e túmulo dos seres. Todos esses elementos corroboram o enigma da comunidade de Argemiro, Santo, Nicoto, Junta e tantos mais. Um enigma a ser destruído para que a ordem vigente prevaleça, tal como em Canudos, cuja história antes de ser incorporada às historiografias, foi narrada por Euclides da Cunha em Os Sertões. Esse texto, sem se deter com fronteiras discursivas, trouxe à luz o combate travado nas trevas entre as expedições militares da Nação republicana positivista e os camponeses liderados por Antônio Conselheiro. Através da narrativa euclidiana, o centro (representado pelas capitais) tomou conhecimento de que em suas margens (O sertão), o Outro apontava sua existência. Ao referir-me a Canudos, relaciono ficção e história por meio de um conceito cunhado pelo cientista político Benedict Anderson: o de comunidade imaginada. Vila Real e Canudos são comunidades, mas no sentido de terem suas existências corporificadas por narrativas (ANDERSON, 1989). Narrativas sobre a liminaridade performática/enigmática da Nação. As últimas palavras do narrador ubaldiano, cabem para o grupo de Argemiro e para o de Antonio Conselheiro, corroborando a permanência da auteridade, mesmo que ela seja empurrada para as sombras, mesmo que ela se configure apenas como narrativa. Leia-se:

“(...) e lá ficaram para combater o que tinha sido tomado sem razão. E não se sabe o resultado, mas se cobriram de poeira e glória e até hoje estão pelo sertão e os gritos que deram talvez se ouçam ainda agora. Tal como se conta esta história pelas estradas, pelos caminhos e pelas vilas, onde quer que haja um viajante e uma esperança e onde quer que um olho se ponha a fitar o horizonte" (RIBEIRO, 1979, pp. 176-177).

\section{Referências bibliográficas}

BENJAMIN, Walter. Sobre o conceito de história. In: Magia e técnica, arte e politica. São Paulo: Brasiliense, 1985.

BHABHA, Homi K. Disseminação: tempo, narrativa e as margens da nação moderna. Belo Horizonte: UFMG, 1994.

HOBSBAWM, Eric. Naçôes e nacionalismo desde 1780. Rio de Janeiro: Paz e Terra, 1988.

LEVI-STRAUSS, Claude. Tristes trópicos. Lisboa: Portugália Editores, 1976.

PIRES, Antonia Cristina de Alencar. A Outra História - (Des) construções: memória e identidade cultural em Viva o povo brasileiro. Belo Horizonte: FALE/ UFMG, 2000. Tese de Doutorado.

PIRES, Antonia Cristina de Alencar. Laços desatados: o esfacelamento das referências em tempos de guerra flagrado em imagens ficcionais e fotográficas. Dubito ergo Sun: sítio cético de literatura e filosofia/Teoria da literatura, 2002 disponível em <HTTP// WWW.dubitoergosun.com.br

POLLACK, Michael. Memória, esquecimento, silêncio. Estudos literários, São Paulo, v. 3, p. 3-15, 1989.

RIBEIRO, João Ubaldo. Vila Real. Rio de Janeiro: Nova Fronteira, 1979. 